\title{
A Case Study on the Effect of Imagery Training for Elite Archers
}

\author{
of South Korea \\ Youngsook Kim ${ }^{\mathrm{a}}$ \& Taiseok Chang ${ }^{\mathrm{b}_{*}}$ \\ ${ }^{a}$ Senior researcher, Department of Sports Science, Korea institute of Sport Science \\ ${ }^{b}$ Researcher, Department of Sports Science, Korea institute of Sport Science
}

\begin{abstract}
The present study aimed to test the effect of imagery training based on neurofeedback in elite archers of South Korea. Imagery training was provided to six elite archers, who imagined shooting three arrows in a set for a total of eight sessions. During imagery training, actual sounds recorded from an international archery Competition were played and Neurofeedback training was provided in a laboratory. In order to accurately measure EEG (Electroencephalogram), the archers were sufficiently rested, and the external environments were controlled before training began to prevent interference by artifacts. EEG was measured while the archers performed imagery training; real-time feedback was provided using vibrations when the waveform of beta waves was outside of the threshold determined for each archer. In addition, to test the effect of imagery training, scales assessing sports competitive state anxiety and sports imagery were administered before and after training, and pre-post changes were assessed. The results showed that in all archers, beta waves stabilized and vibration frequency decreased in post-measurement. Anxiety levels were reduced and imagery ability improved. Based on the findings, real-time neurofeedback training is believed to enhance athletes' self-regulation.
\end{abstract}

Key words: neurofeedback, elite athletes, archery, imagery training, beta waves

\section{Introduction}

Among various psychological techniques, mental imagery is one of psychological skills that are most often used by athletes. A majority of high-performance athletes practice imagery training. More than $90 \%$ of athletes who competed in mega-events such as the Olympics have used imagery training. They applied imagery to practice skills and strategies while training

Submitted : 28 September 2020

Revised : 30 October 2020

Accepted : 26 November 2020

Correspondence : jaygoon@skku.edu for the Olympics, as well as during the game itself, to concentrate and set their goals (Murphy, Jowdy, \& Dutschi, 1989; Orlick \& Patrington, 1988; Smith, 1987). imagery training is not exclusive to athletes; it is also recommended by sport leaders and psychologists, which demonstrates that imagery is an important psychological skill associated with athletes' performance (Battaglia, D'Artibale, Fiorilli, Piazza, Tsopani, Giombini, Calcagno, \& di Cagno, 2014; Gould, Tammen, Murphy, \& May, 1989; Hall \& Rogers, 1989).

Imagery training refers to imagining a past performance experience by summoning all modes of 
physical sensation or creating a new experience based on past performances (Kosslym, Thompson, Sukel, \& Alpert, 2005; Vealey \& Greenleaf, 2001; Vealey \& Walter, 1993). Specific skills or overall performance can be improved by imagery individually and without the use of physical practice. Numerous studies conducted outside South Korea have reported that imagery has helped athletes enhance their confidence and flow state (Callow, Hardy, \& Hall, 2001; Koehn, Morris, \& Watt, 2014), as well as their skill acquisition, motor performance, and competition performance (Bar-Eli, Dreshman, Blumenstein, \& Weinstein, 2002; Battaglia, et al., 2014). South Korean studies have revealed that imagery training in archery, rifle shooting, and golf has improved athletes' performance (Kwon, Kim, Jeon, Lee, Kim, \& Woo, 2009; Lee \& Youn, 2001; Lee \& Kim, 2004). To summarize previous discoveries, it is thought that imagery training has a positive impact on athletes' performance. Studies have shown that brain activity similar to that occurring during physical performance is observed during imagery training alone. Leung, Spittle, and Kidgell (2013) claimed that both motor imagery and actual movement activate the neural networks, and various areas of the brain are involved in physical training-related corticospinal adaptations. In addition, imagery includes temporal and spatial information, as well as the movements that entail the use of muscles and joints (Ste-Marie, Law, Rymala, Craig Halld, \& McCullagh., 2012). Thus, a question arises regarding whether imagery alone can induce the same brain activity as physical exercise. In order to address this question, Milton, Solodkin, Hlustik, and Small (2007) measured the region of interest (ROI) using fMRI (Funtional magnetic resonance imaging) in novice and advanced golfers during pre-shot routines. They found that in advanced golfers' brains, the superior parietal lobule, dorsal lateral premotor area, and occipital area were activated, whereas in novice golfers' brains, the posterior cingulate, amygdala, and basal ganglia were activated. This suggests that differences in neural efficiency during motor planning exist between novices and advanced golfers. DeBettencourt, Cohen, Lee, Norman, and Turk-Browne (2015) affirmed that training the brain involves attention control and the ability to control attention develops by training. Consequently, general cognitive functioning is improved.

For best performance, athletes should have an awareness of their own psychological state, and be able to control this state and create an imagery of a successful performance during the competition. Self-regulation and imagery ability are crucial. Self-regulation is an essential component in the psychometrics and psychological interventions performed to boost sports performance (Crews, 1993; Crews, Lochbaum, \& Karloy, 2001; Hatfield \& Hillman, 2001; Kirschenbaum, 1984; Schwartz, 1979; Zaichkowsky, 1983; Zaichkowsky \& Fuchs, 1988, 1989). Athletes use biofeedback techniques to improve self-regulation. Biofeedback is a process in which individuals observe psychophysiological events (which are typically difficult to be aware of) with the help of an apparatus, and learn to maintain an ideal physiological state through their own efforts (Kim \& Lee, 2007). Biofeedback is employed by monitoring the electrical activities of the heart (EKG), muscles (EMG), skin (SC), and brain (EEG). An advantage of using a biofeedback apparatus is that it can detect internal bodily functions more accurately and in further detail than human perception can (Gatchel \& Price, 1979).

Additionally, psychophysiological measurements like biofeedback provide objective data, unlike self-report questionnaires (Blumenstein, Bar-Eli, \& Tenenbaum, 1995, 2002; Hatfield \& Landers, 1983; Landers, 1985). Biofeedback training has been reported to positively impact athletes' performance (Blumenstein, Bar-Eli, \& Tenenbaum, 1995; Collins, 1995; Hatfield \& Landers, 1987; Petruzello, Landers, \& Salazar, 1991; Zachkowsky \& Fuchs, 1988). One of the various techniques used for biofeedback is neurofeedback, an approach based on the electrical activities of the brain (EEG). Neurofeedback is a training procedure designed 
to alter brain function by modifying EEG (Choi, 2010). EEG can be altered in a desired direction by repeating the process of collecting brainwave data through electrodes attached to the scalp and showing the analyzed information to the subject. In other words, neurofeedback is a biofeedback technique using EEG, through which athletes can regulate brain waves by intentionally generating a positive EEG to improve cognitive capacity and perform to the best of their ability (Sim, 2004).

Brain waves are largely grouped into five bands from high- to low-frequency waves (Gruzelier \& Egner, 2004). Of the frequency bands, beta waves are related to active problem-solving, cognitive activity, outer focus, and attention. Beta wave activity takes place while learning is occurring, rather than when learning is complete (Barlow, Lehrer, Woolfolk, \& Sime, 2007). Previous studies have stressed the importance of the change in beta waves with the application of real-time neurofeedback training in athletes.

Neurofeedback may be utilized to reduce competition anxiety. When athletes experience anxiety during a competition, their muscles stiffen, concentration declines because of hyper alertness, and negative thoughts and feelings (such as frustration and helplessness) can emerge, which consequently affect performance level. Studies in which athletes have employed neurofeedback (Sim, 2004; Hong \& Lee, 2007) have demonstrated that competition anxiety decreased as a result. A recent study that investigated the relationship between the frontal EEG asymmetry score and competition anxiety (Hong \& Woo, 2013) reported that competitive trait anxiety is associated with frontal cortical activity; moreover, it suggested that neurofeedback training, when harnessed to decrease bilateral frontal cortical activity at rest, may help to reduce competitive trait anxiety. Overall, based on studies conducted both in and outside South Korea, neurofeedback is an appropriate training technique in sports by means of measuring and evaluating athletes' levels of psychological anxiety and relaxation, as well as the emotional changes they experience. Neurofeedback training in past studies consisted of gauging physiological signals and providing feedback after training is complete. One drawback of this method is that feedback is not provided during training. A training technique in which athletes can self-regulate while receiving real-time feedback may be more effective.

In archery, the interaction between psychological and physiological factors critically affects archers' performance (Paul, Ganesan, Sandhu, \& Simon, 2012). An investigation into the features of the imageries used by the top, world-class South Korean elite archers revealed that archers used visual and kinesthetic imageries (Lee, Kim, Kim, \& Hwang, 2009). However, no study has examined imagery intervention based on recent imagery theory or via the use of the cognitive neuroscience approach for elite athletes in archery, a field in which psychological factors account for more than $50 \%$ of performance (Yun, Kim, \& Lim, 2006). It is believed that neurofeedback-based imagery training will enhance brain activity and efficiency in athletes, and improve their imagery ability by objectively measuring changes in the brain and offering feedback in real time during training. Additionally, imagery training grounded in neurofeedback will have a positive impact on certain psychological aspects, such as athletes' confidence and flow state, and eventually help them improve their performance. This study was conducted with the aim of providing South Korean elitearchers with imagery training based on a real-time neurofeedback system and testing its effect.

\section{Methods}

The aims of the study was to give athletes imagery training that utilizes sounds from genuine competitions, test the effects of the training by scrutinizing the differences in brain activity in the motor area, and assess competitive state and trait anxiety and sports imagery using psychometrically-tested questionnaires. 
This chapter presents background information on the researchers and participants, experimental task and instruments, experimental design and procedure, and data analysis methods.

\section{Participants}

The participants included three men and three women elite archers, with a mean age of $26.5( \pm 3.2)$ years. The participants are members of the Korean Archery Association -.

Table. 1 Basic information on the participants

\begin{tabular}{cccc}
\hline \hline ID & Sex & Age & Number of years in archery \\
\hline A & Male & 36 & 22 \\
\hline B & Male & 25 & 14 \\
\hline C & Male & 25 & 13 \\
\hline D & Female & 27 & 15 \\
\hline E & Female & 23 & 12 \\
\hline F & Female & 23 & 12 \\
\hline \hline
\end{tabular}

The participants were informed of the study's purposes and the experimental task; they signed a written consent form before participating in the study.

\section{Methodology}

\subsubsection{Experimental task}

To create the experimental task, an imagery training program was developed that includes sounds from the beginning of international archery competition, as well as beeps to ensure that the participants could feel as if they were in the field. The details of the imagery training were as follows: The participants were instructed to form an image in their minds, starting from the time an announcement was made (approximately five minutes before the start of the competition) until they shot three arrows in the first end. This time frame was determined by conferring with veteran archery experts. The experts believed that archers feel most anxious and tense, both internally and externally, before the start of a competition and during the first end. In the imagery training program, the auditory data of an actual World Cup competition was used, and the auditory information was given the same timing as an actual competition. Imagery training was performed in the lab for 30 minutes per session for a total of eight sessions.

\subsubsection{Apparatus and measurement scales}

To examine the effects of imagery training, the following experimental instruments were used for the pre- and post-tests.

\subsubsection{Brainwave measurements}

To accurately determine EEG, the participants relaxed for approximately 10 minutes after arriving at the lab. Next, the experiment was prepared. Accessories worn by the participants were removed and the lighting was adjusted to prevent artifact interference from environmental sources.

EEG was gauged with WEEG-32 (LXE3232-RF), a device manufactured by Laxtha. To determine sites for electrodes, the scalp was measured with a tape and locations were marked in accordance with the international 10-20 system. Four points comprised of the nasion, inion, and the left and right preauricular points were used as references, and electrodes were attached along each line to connect the reference points at intervals of $10 \%$ and $20 \%$. Prior to the main experiment, a pilot test with a one-minute imagery training module was conducted using the competition sounds, with a total of 16-channel electrodes located in the prefrontal (Fp1 and Fp2), frontal (F3, Fz, and F4), temporal (T3, T4, T5, and T6), and parietal (C3, $\mathrm{Cz}, \mathrm{C} 4, \mathrm{P} 3, \mathrm{Pz}$, and P4) cortices. The pilot test showed that beta wave activity occurred in $\mathrm{C} 3, \mathrm{Cz}$, and $\mathrm{C} 4$ in all six participants. Subsequently, during the main experiment, electrodes were attached to a total of three areas $(\mathrm{C} 3, \mathrm{Cz}$, and $\mathrm{C} 4)$. Before attaching the electrodes, the areas on the scalp were cleansed with a cotton swab 
to maintain impedance beneath $5 \mathrm{k}$ ohm. The cutoff frequency was set to $0.5 \mathrm{~Hz}$ in the low-frequency band and $100 \mathrm{~Hz}$ in the high-frequency band. To prevent (physiological and non-physiological) artifacts from interfering during the experiment, the participants were alerted of relevant precautions beforehand. When a 60 $\mathrm{Hz}$ noise, an electrical noise, or a cardiac signal occurred during the experiment, the electrodes were adjusted, and impedance was reduced to less than $5 \mathrm{k}$ ohm before measurement was resumed.

To provide real-time neurofeedback, the Labview-based software used in the work of Kim, Lee,
Cho, and Chang (2016) was modified to fit the study's purposes, as shown in Figure 2. To provide real-time feedback, the software was designed to generate vibrations if the absolute value of beta waves oscillating during the imagery training exceeded a stanine score of $8(89 \%)$ (Mertler, 2007). To establish a threshold for each participant, the EEG was gauged for one minute after the experimental preparation was complete. Based on this data, the threshold was computed and entered into the Labview program before the main experiment began.
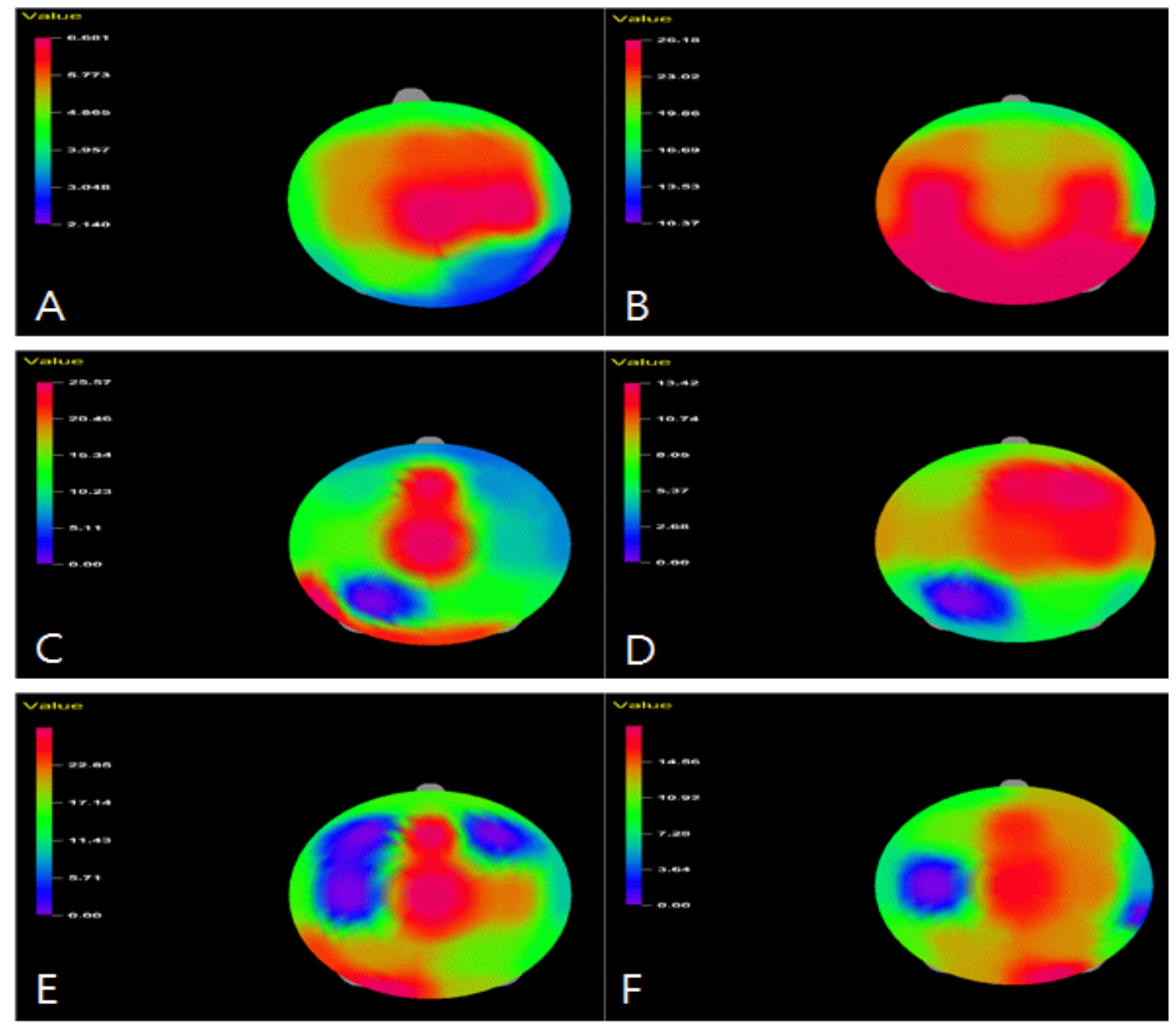

Figure 1. Pilot test results 


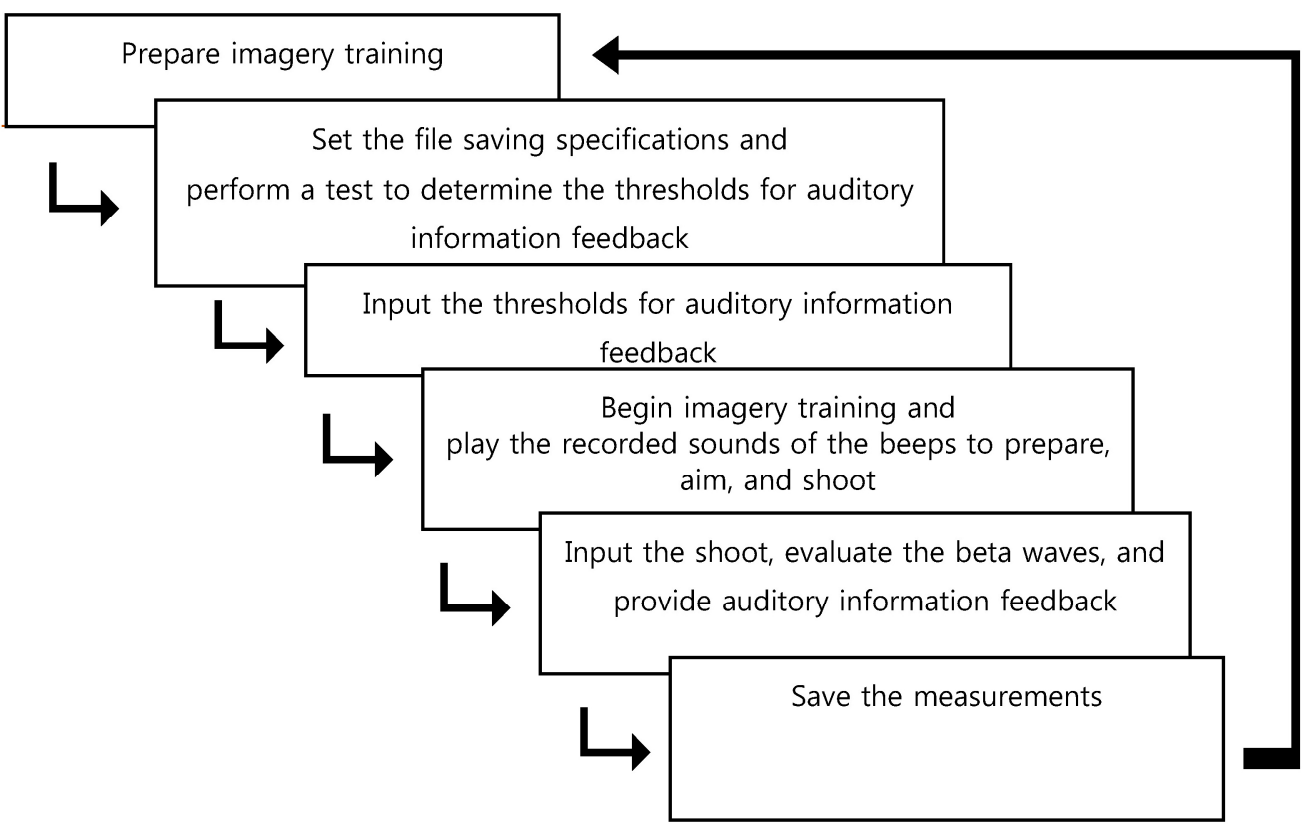

Figure 2. The structure and flow of the Labview program

\subsubsection{Measurement scales}

\section{Competitive State Anxiety Inventory (CSAI-2)}

To assess competitive state anxiety and confidence levels before and after neurofeedback-based imagery training, the Competitive State Anxiety Inventory-2 (CSAI-2), developed by Martens et al. (1990) and translated into Korean by Lee et al. (1993), was used. The CSAI-2 included three subdomains of cognitive state anxiety, somatic state anxiety, and self-confidence; each subdomain consisted of nine items on a five-point Likert scale. The reliability of each subdomain was .84 for cognitive state anxiety, .76 for somatic state anxiety, and .83 for self-confidence.

\section{Sport Competition Anxiety Test (SCAT)}

To determine trait anxiety in a sports situation, the Sport Competition Anxiety Test (SCAT) developed by Martens et al. (1990) was employed. The test-retest reliability of the SCAT was between .57-93, and the internal consistency coefficient was between .95-97.

\section{Sport Imagery Questionnaire (SIQ)}

The Sport Imagery Questionnaire (SIQ) elaborated by Martens (1987) was applied to establish imagery ability before and after neurofeedback-based imagery training. Imagery ability was evaluated by adding the scores of the five domains, visual, auditory, and kinesthetic imageries, the mood associated with imagery, and control over imagery.

\subsection{Experimental procedure}

When the participants arrived at the lab, they were seated in a comfortable chair and assessed for psychological calm or tension, physical fatigue, and physiological condition. Additionally, any accessories that might interfere with electrical signals were removed. Afterward, neurofeedback-based imagery training was briefly introduced to increase their understanding of the study, and the need to take precautions to avoid excessive movement during the training was emphasized. 


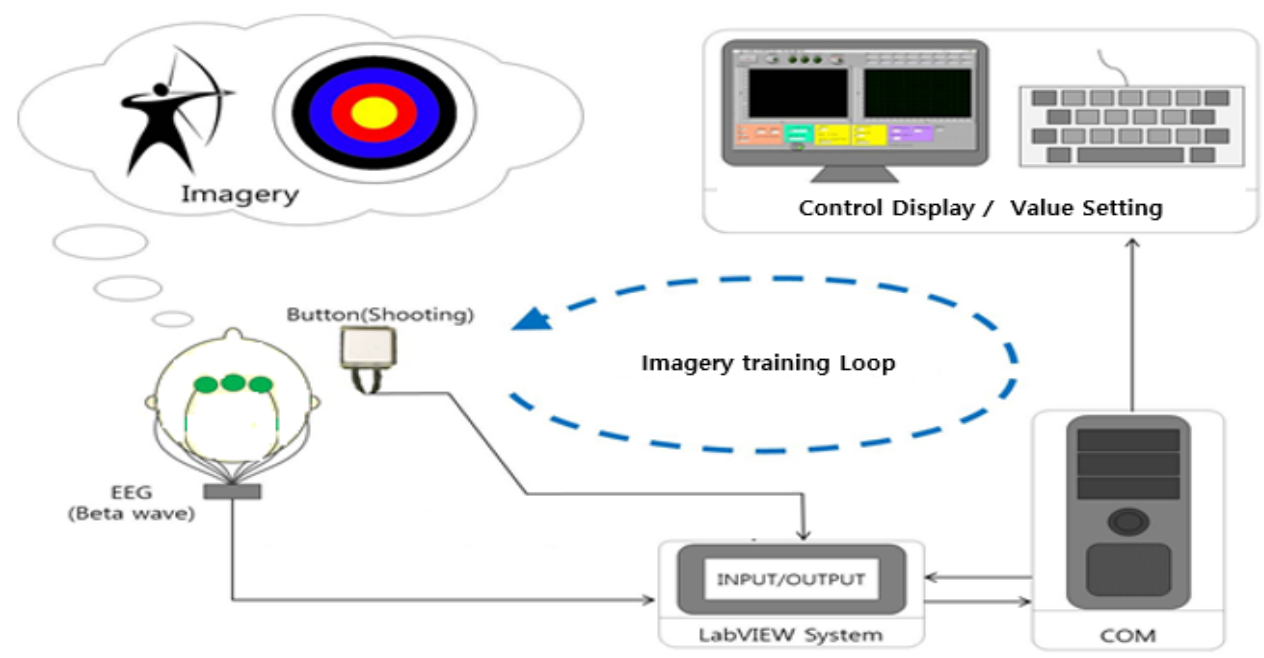

Figure 3. The structure and flow of the Labview program

After the electrodes were attached, whether or not EEG was measured without problems was tested using a brainwave analysis program. After the preparation for imagery training was complete, the participants were instructed to calm their minds with breath control and muscle relaxation. Once they were ready for training, neurofeedback-based imagery training commenced with the participants' eyes closed. The details of the imagery training were as follows: The participants were instructed to create a mental image of a scene in which they were shooting an arrow from their perspective. This imagery was determined based on expert opinion that during a competition, archers are most tense and anxious before the start of a competition until the first end is over. Accordingly, auditory information was only presented for the time period until three shots in the first end, including beeps to announce five minutes before the start, to aim, and to begin shooting. The auditory information was recorded at an actual competition, and was presented with the same timing of the flow during the competition. The participants were instructed to maintain a clear image of themselves successfully shooting arrows (the task) by summoning all modes of sensation, while auditory information was presented as described above.

\section{Statistics}

To test the effects of the real-time neurofeedback system, brainwave measurements were saved in Excel. The measurement data were filtered using BatchPro-Addon (software to preprocess brainwave signals) to remove noise and extract beta waves, before conducting data analysis.

Pilot test data and the beta wave data, measured during the stable state, were collected and saved in Excel. The criterion for a stable interval to determine beta wave oscillation was established through filtering and the first computation. The data obtained before and after the experimental treatment were analyzed with SPSS Windows (Version 21.0). A t-test was performed to compare the conditions before and after the experimental treatment; statistical significance was determined if the probability value ( $\mathrm{p}$-value) was $\mathrm{p}<.05$. The participants' psychological state during the competition was examined based on the change in beta waves, determined during imagery training via data exploration and visualization. The frequency and rate 
of vibration were computed based on the difference between the beta wave measurements and the threshold. A t-test was performed to test the change in beta waves according to the vibrations. The statistical significance level was set at $\alpha=.05$ for all tests.

\section{Results}

1. Changes in neural activity in neurofeedback training

The archers performed imagery training with electrodes attached at $\mathrm{C} 3, \mathrm{Cz}$, and $\mathrm{C} 4$ while receiving real-time feedback. Feedback was provided using a small vibrating motor that generated vibrations when neural activities in the three areas were outside of a threshold. To establish the threshold, in each of the eight sessions, the archers performed imagery training of shooting three arrows (one set) before the main experiment proceeded. To explore changes in the vibration rate and frequency, relevant data were divided separately into before and after sets from each of the three shoots for analysis.

\subsection{Changes in beta waves}

The following tables and figures outline the analyses and results of the changes in beta waves, as well as of the changes in feedback according to the difference in beta waves. Table 2 portrays the outcomes of the analyses conducted to compare the beta waves, as well as the vibration frequency before and after the experimental treatment, based on the data collected while the archers imagined three shots for 20 seconds per shot. Descriptive statistics are also presented for each archer. The analyses of the data collected for over 500 data points per second indicated that in all archers, changes in beta waves and vibration frequency were statistically significant at the $p<.05$ level.

However, the measurement values of the beta waves were very small. Thus, the statistical differences were miniscule. Differences in the beta waves and vibration frequency (which were extremely minute given the characteristics of the neurological mechanism) were scrutinized comparatively using the results from counseling and psychological testing to explain the psychological changes suggested by the small shift in brainwave measurements. In addition, the findings regarding the comparisons among the three shots and

Table 2. T-test results of pre-post changes in beta waves and vibration frequency during imagery training

\begin{tabular}{|c|c|c|c|c|c|c|c|c|}
\hline \multirow{2}{*}{ ID } & & \multirow{2}{*}{ Shooting } & \multicolumn{2}{|c|}{ Pre } & \multicolumn{2}{|c|}{ Post } & \multirow{2}{*}{$\mathrm{t}$} & \multirow{2}{*}{$\mathrm{p}$} \\
\hline & & & M & SD & M & SD & & \\
\hline \multirow{2}{*}{ A } & \multirow{2}{*}{ Total } & Beta wave & .000219 & .000059 & .000212 & .000057 & 8.841 & .000 \\
\hline & & Vibration frequency & .000040 & .000059 & .000032 & .000057 & 10.117 & .000 \\
\hline \multirow{2}{*}{ B } & \multirow{2}{*}{ Total } & Beta wave & .000376 & .000165 & .000349 & .000214 & 10.398 & .000 \\
\hline & & Vibration frequency & -.000189 & .000165 & -.000260 & .000214 & 27.223 & .000 \\
\hline \multirow{2}{*}{$\mathrm{C}$} & \multirow{2}{*}{ Total } & Beta wave & .000186 & .000120 & .000157 & .000065 & 22.017 & .000 \\
\hline & & Vibration frequency & -.000623 & .000120 & -.000372 & .000065 & -192.012 & .000 \\
\hline \multirow{2}{*}{$\mathrm{D}$} & \multirow{2}{*}{ Total } & Beta wave & .000376 & .000130 & .000393 & .000222 & -6.998 & .000 \\
\hline & & Vibration frequency & -.000300 & .000130 & -.000437 & .000222 & 55.211 & .000 \\
\hline \multirow{2}{*}{$\mathrm{E}$} & \multirow{2}{*}{ Total } & Beta wave & .000410 & .000226 & .000259 & .000108 & 62.617 & .000 \\
\hline & & Vibration frequency & .000074 & .000226 & -.000111 & .000108 & 76.679 & .000 \\
\hline \multirow{2}{*}{$\mathrm{F}$} & \multirow{2}{*}{ Total } & Beta wave & .000194 & .000080 & .000191 & .000069 & 2.392 & .000 \\
\hline & & Vibration frequency & -.000018 & .000080 & -.000086 & .000069 & 67.073 & .000 \\
\hline
\end{tabular}


its changes were visualized using box plots and multiple line graphs.

1.2 Mean pre-post changes in beta waves and vibration frequency during imagery training in individual archers

To assess whether a transition from calmness to agitation occurred during imagery training and to provide vibration feedback, a baseline to establish a stable state in beta waves was measured both before and after the experimental treatment. The mean value of the beta waves in the stable state, corresponding to a stanine score of 8 (cumulatively $89 \%$ ), was used as the threshold.

Overall, beta wave activity decreased from a mean of .000219 ( \pm .000059$)$ to a mean of .000212 ( \pm .000057$)$. Although the values were similar, the pre-post t-test revealed that the difference was statistically significant at the level of $\mathrm{p}<.05$. Moreover, the distributions of pre- and post-measurements were similar.

The mean vibration frequency was a positive value, and decreased similarly like the decline in beta waves. The criterion for assessing pre-post vibration frequency rose slightly from a mean of.000117 ( \pm .000049$)$ to a mean of .000135 ( \pm .000051$)$. Accordingly, vibration frequency fell from a mean of .000040 $( \pm .000059)$ to a mean of $.000032( \pm .000057)$.

\subsection{Vibration rate}

Changes in the vibration rate were examined by dividing the data into pre- and post-shot categories and separately analyzing each of the three shots within a set. Table 2 depicts the descriptive statistics on the first shot across all sets during neurofeedback-based imagery

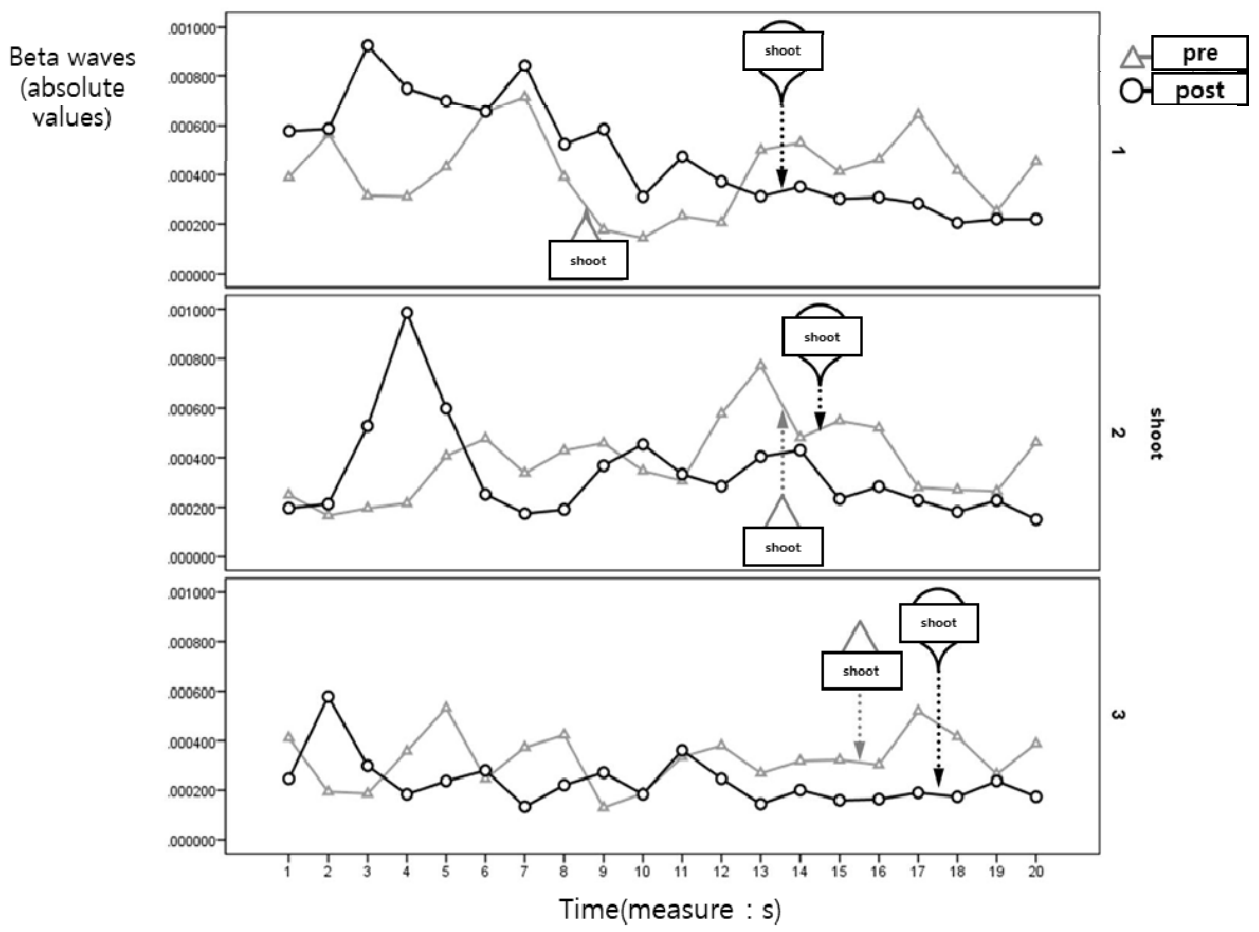

Figure 4. Changes in beta waves over 20 seconds before and after a shoot, across all archers

$\mathrm{Y}$ axis: Beta waves (absolute values) within each graph: Shoot, Shoot
$\mathrm{X}$ axis: Time (seconds)

Key to the symbols: Pre- 
training. An investigation of the data per shot signaled that the vibrational rate declined in the second and third shots compared to the first in Archers B and D. In all other participants, there was no significant change in vibration between the before and after shots.

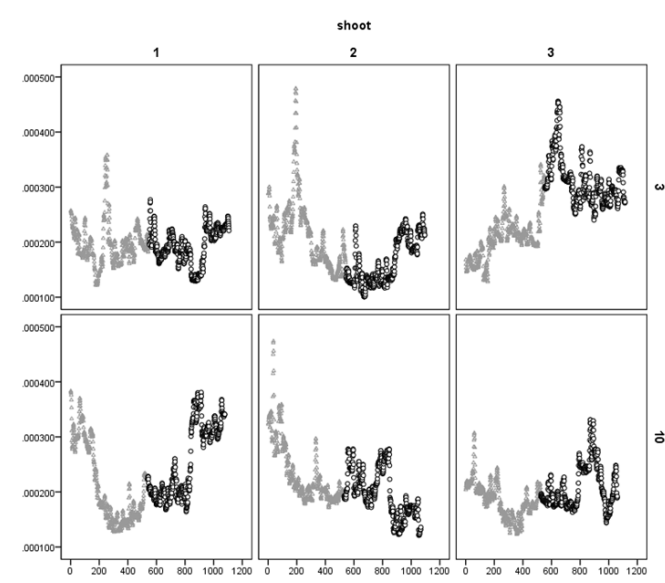

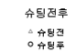

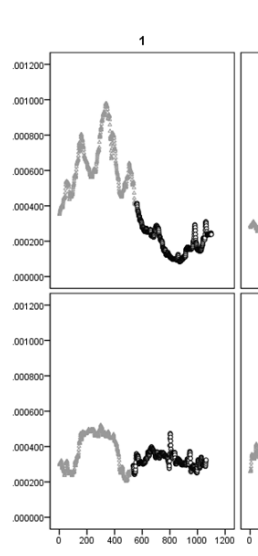

shoot
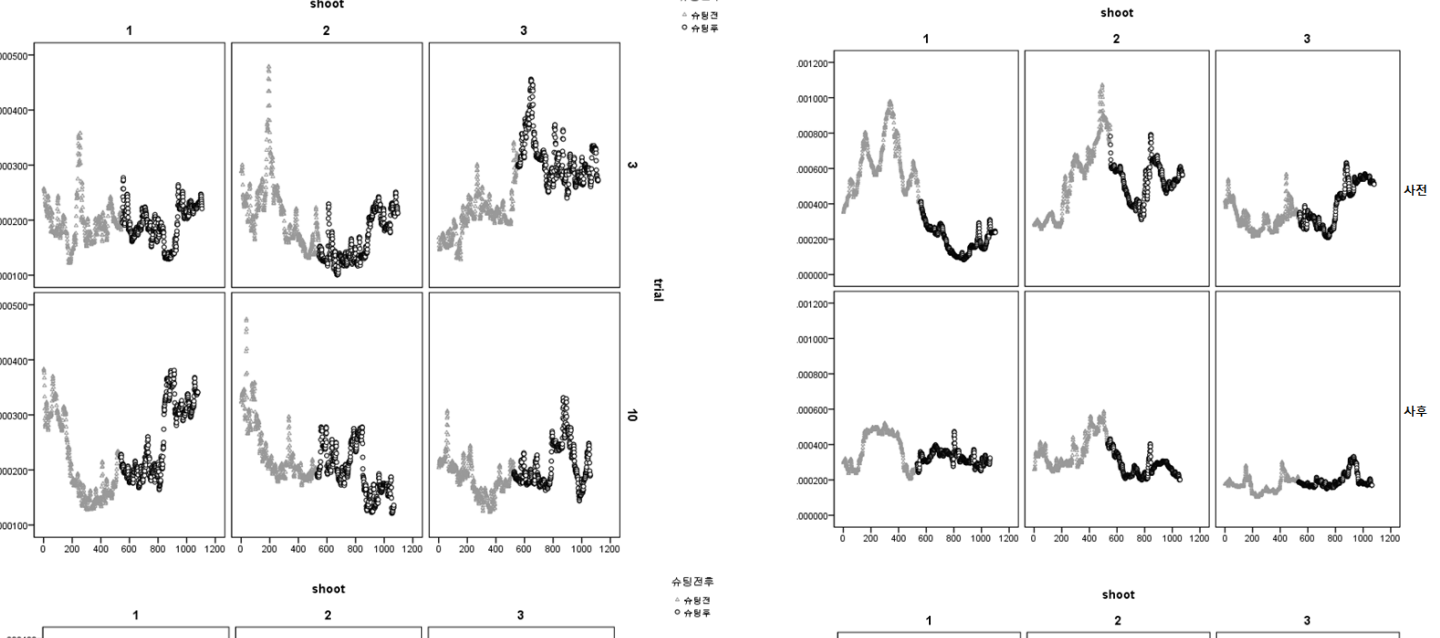

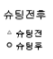
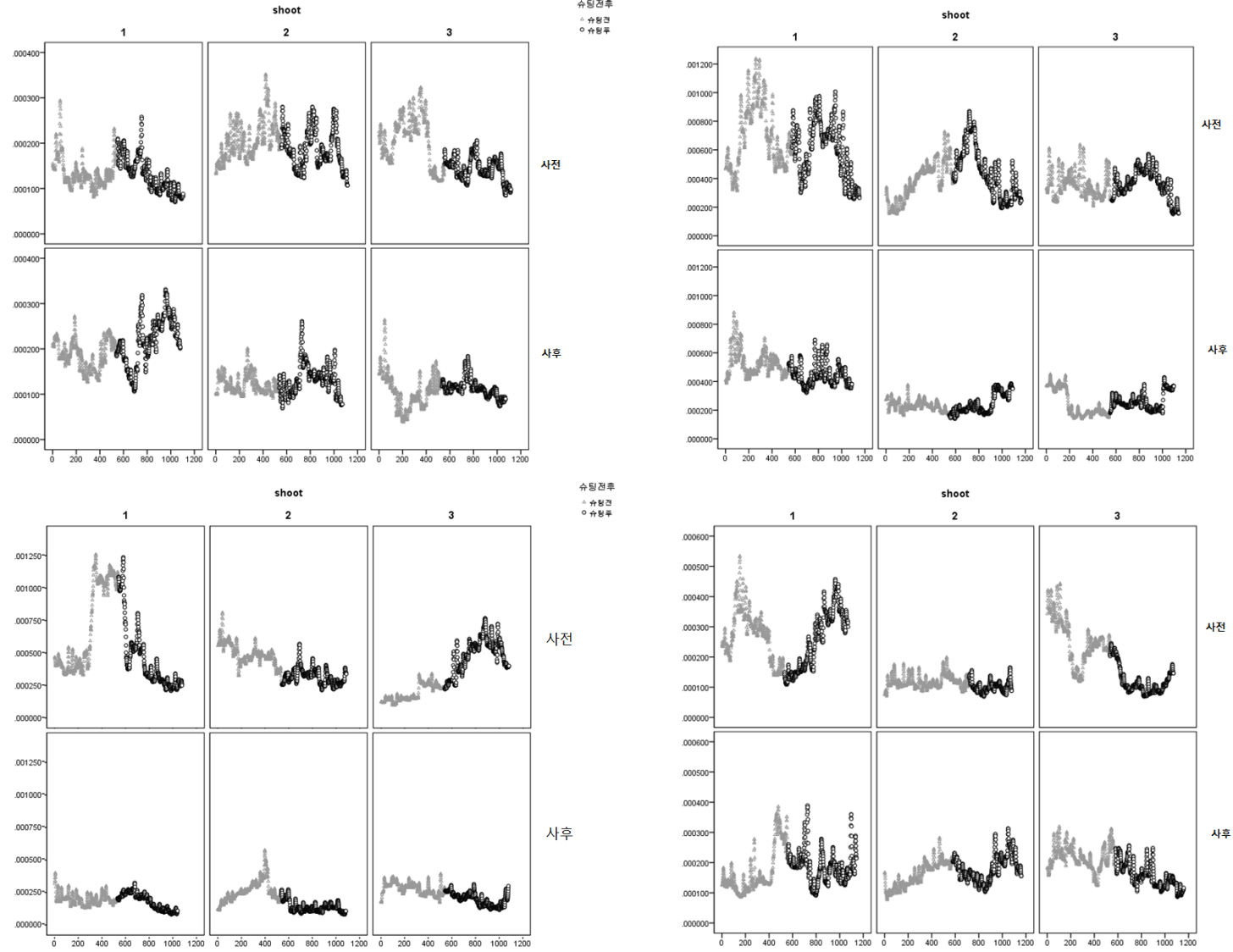

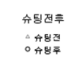

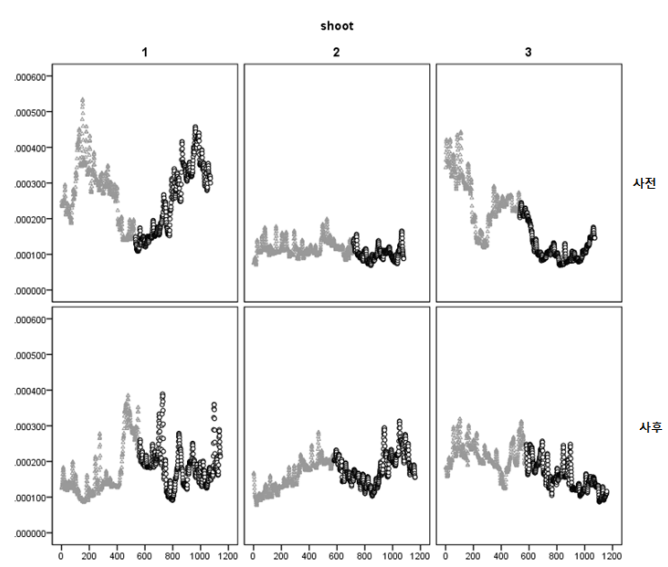

Figure 5. Pre-post changes in beta waves in intervals of 20 seconds in individual archers

(Upper left: Archer A, upper right: Archer B, middle left: Archer C, middle right: Archer D, lower left: Archer E, and lower right: Archer F

Upper graphs show pre-measurements, and lower graphs show post-measurements) 
Table 3. Descriptive statistics on vibration frequency and rate during neurofeedback training

\begin{tabular}{|c|c|c|c|c|c|}
\hline & & \multicolumn{4}{|c|}{1 set } \\
\hline \multicolumn{2}{|c|}{ ID / Categories } & \multicolumn{2}{|c|}{ Pre-shoot } & \multicolumn{2}{|c|}{ Post-shoot } \\
\hline & & Frequency & $\%$ & Frequency & $\%$ \\
\hline \multirow{2}{*}{ A } & No sound & 2185 & $41.3 \%$ & 2026 & $36.9 \%$ \\
\hline & Vibration & 3101 & $58.7 \%$ & 3466 & $63.1 \%$ \\
\hline \multirow{2}{*}{ B } & No sound & 3147 & $82.6 \%$ & 3432 & $90.1 \%$ \\
\hline & Vibration & 662 & $17.4 \%$ & 377 & $9.9 \%$ \\
\hline \multirow{2}{*}{$\mathrm{C}$} & No sound & 3481 & $91.9 \%$ & 3414 & $89.4 \%$ \\
\hline & Vibration & 307 & $8.1 \%$ & 406 & $10.6 \%$ \\
\hline \multirow{2}{*}{ D } & No sound & 5116 & $84.4 \%$ & 5547 & $90.6 \%$ \\
\hline & Vibration & 946 & $15.6 \%$ & 573 & $9.4 \%$ \\
\hline \multirow{2}{*}{$\mathrm{E}$} & No sound & 3610 & $76.4 \%$ & 3668 & $77.2 \%$ \\
\hline & Vibration & 1114 & $23.6 \%$ & 1084 & $22.8 \%$ \\
\hline \multirow{2}{*}{$\mathrm{F}$} & No sound & 4421 & $67.6 \%$ & 4722 & $70.9 \%$ \\
\hline & Vibration & 2123 & $32.4 \%$ & 1938 & $29.1 \%$ \\
\hline
\end{tabular}

2. Between-archer comparison in changes in anxiety and imagery ability

In this study, imagery training was provided to archers by employing a real-time neurofeedback system, which was developed specifically for archery; its effects were tested by measuring trait anxiety, state anxiety, and imagery ability before and after training.

In Archer A, there was a slight change in state anxiety before and after neurofeedback-based imagery training. However, he improved in all the domains of imagery ability. In Archer B, state anxiety decreased somewhat during post-measurement when compared to pre-measurement. All the domains of imagery ability (with the exception of control) improved. Improvement was the greatest in terms of kinesthesia and the mood state.

In Archer C, cognitive anxiety (in terms of state anxiety) reduced slightly post-measurement; trait anxiety also declined. Since Archer C typically had lower levels of cognitive and somatic anxiety than the others, there was no marked pre-post change. However, he improved in all the domains of imagery ability, especially kinesthetic imagery, which was enhanced considerably. This implies that he may rely heavily on kinesthetics while keeping an imagery of archery performance in mind.

In Archer D, state and trait anxiety reduced, and all domains of imagery ability improved by $2-4$ points. In Archer E, cognitive and somatic anxiety (in terms of state anxiety) rose very slightly; however, there was little change in trait anxiety. Regarding imagery ability, a slight enhancement was observed in the visual and

Table 4. Overall pre- and post-means (and the differences) of anxiety and imagery ability

\begin{tabular}{crrr}
\hline \hline State anxiety & Pre & Post & Pre-post difference \\
\hline $\begin{array}{c}\text { Cognitive } \\
\text { anxiety }\end{array}$ & 1.88 & 1.85 & -0.33 \\
\hline $\begin{array}{c}\text { Somatic } \\
\text { anxiety }\end{array}$ & 1.70 & 1.605 & -0.095 \\
\hline Trait anxiety & 16.33 & 16 & -0.33 \\
\hline \hline Imagery & Pre & Post & Pre-post difference \\
\hline Visual & 8.166 & 11 & +2.833 \\
\hline Auditory & 8 & 10.166 & +2.166 \\
\hline Kinesthetic & 8.5 & 12.166 & +3.833 \\
\hline Mood & 7.66 & 10.66 & +3 \\
\hline Control & 8 & 10.5 & +2.5 \\
\hline \hline
\end{tabular}


kinesthetic domains, with little change in mood or control, and a slight decrease in the auditory domain. For Archer F, cognitive anxiety (in terms of state anxiety) moderately increased, but there was little change in somatic or trait anxiety. As for imagery ability, minor change occurred in the auditory domain, but some improvements were noted in the domains of visual, kinesthetic, mood state, and control.

\section{Discussion}

The goals of this study were to modify and improve a real-time, brainwave-based neurofeedback system for imagery training and test the effects of neurofeedback training by using an imagery training program for South Korean elite archers. To achieve these goals, the effects were analyzed by examining changes in EEG real time and providing vibrational feedback to help the archers effectively perform imagery, and providing self-regulatory imagery training so that they could successfully cope when vibrations were generated.

In this chapter, the significance of the findings according to these goals and in relation to previous studies are discussed.

\section{Changes in beta waves and vibration in neurofeedback training}

Of the types of brain waves, beta waves are related to top-down control in attention processing (that is, the mode of information processing based on the learner's prior knowledge) and are involved in visual-motor attention (Buschman \& Miller, 2007; Siegel, Donnerr, $\&$ Engel, 2012). In addition, beta wave activity occurs during the planning and execution of a movement (Engel and Fries, 2010). Numerous studies have shown that beta wave activity increases while a movement is planned and before it is executed, and decreases when the movement begins to be executed (Stancak and Pfurtscheller, 1996; Erbil and Ungan, 2007; Wheaton, Fridman, Bohlhalter, Vorbach, \& Hallett., 2009, Alegre et al., 2004; Leocani et al.,2001; Zhang et al., 2008).
Beta wave activity can be observed in all the brain areas associated with motor skills, including the motor area, the premotor area, the basal ganglia, the cerebellum, and the peripheral motor system (Baker, 2007; Brown, 2007). The pilot test conducted before the main experiment revealed that brainwave activities in $\mathrm{C} 3, \mathrm{Cz}$, and $\mathrm{C} 4$ increased substantially during imagery training. Thus, for the main experiment, these 3 areas were selected for real-time neurofeedback during imagery training. Likewise, based on the past studies mentioned above, beta waves were chosen to examine any change in the cognitive state during imagery training.

Because the EEG pattern is sensitive to a variety of factors, and the amplitude is different for each measurement. EEG in a stable state was gauged for one minute before EEG-based neurofeedback training during each session, in order to establish a threshold to provide vibrational feedback to each archer. The individualized thresholds were programmed into the devices.

During imagery training, the archers imagined three shots in a set. Under the assumption that the performance of the first shoot would impact subsequent shoots, imagery training was performed in the unit of a set. For Archers A, B, C, and E, the beta wave activity fell from post-measurement to pre-measurement levels. Archer D showed a slight increase in beta wave activity post-measurement. Archer F did not exhibit a clear difference before and after, although it was statistically significant. Regarding changes in vibration, the vibrational rate markedly declined post-measurement in all six archers.

Lander, Petruzzello, Salazar, Crews, Kubitz, Gannon, and Han (1991) investigated whether neurofeedback training using EEG improves not only concentration and confidence but also performance in archers. They found a difference in performance between the archer group that received feedback and the group that did not. Neurofeedback training stabilizes neurophysiological changes (Becerra, Fernandez, Harmony, Caballero, Garcia, Fernandez-Bouzas, Santiago-Rodriguez, \& 
Prado-Alcala, 2006). Shifts that occur in the brain are based on the brain's neuroplasticity mechanism (Ninaus, Kober, Witte, Koschutnig, Neuper, \& Wood, 2015). The previous results are supported by the current study. Because national archers have world-class archery skills, they will perform better if they do neurofeedback training to increase self-regulation before an international competition.

2. Changes in beta waves pre- and post-shooting

Beta wave activity rapidly increases immediately before a movement occurs and decreases when it is about to be executed (Alegre et al., 2004; Loocani et al., 2001; Wheaton et al., 2009; Zhang et al., 2008), which suggests that beta waves activate in the movement planning stage. In this study, after the overall course of 20 seconds was examined, beta waves three seconds before and after the moment of a shoot were studied.

The analysis revealed the following results: In Archer A, the beta wave activity and vibrational rate both fell post-measurement compared to pre-measurement. For this archer, the distribution of beta waves was widespread. In combination with the change in beta waves, this suggests that the stability of EEG improved, but there may have been a fluctuation in competition performance. In Archer B, the range of beta waves gradually reduced post-measurement; the mean value decreased as well. In addition, the pattern of beta waves was more consistent post-measurement compared with pre-measurement, and activity was lowered as the moment of arrow shooting approached. Based on this outcome, there may have been a positive change during imagery training.

For Archer $\mathrm{C}$, based on the results of the beta waves, during imagery training, he seemed to perform while maintaining a very stable state. An examination of the pre- and post-measurements indicated that the distribution of the beta waves became even narrower, implying that the archer consistently maintained a stable state without fluctuation. Regarding change at the moment of shooting, the timing of a shot was faster by an average of 2-4 seconds post-measurement. Hence, his ability to create and embody an imagery may have improved.

With Archer D, the beta wave activity and vibrational rate decreased post-measurement. Similar to Archer A, the distribution of the beta waves tended to be widespread. Based on the distribution and change in beta waves, the stability in EEG likely increased, but there may be fluctuations in the performance level.

In Archer E, the beta wave oscillations were great during the first shoot pre-measurement, but steadily stabilized. Further, post-measurement, the beta wave activity remained stable for all three shots. This archer exhibited a characteristic that the moment of shot was, on an average, at the 18th-19th second. Based on what the archer said during counselling ("After the beep, I was trying to create a detailed image and even use the sensations in my fingertips; this delayed the shooting"), as well as the stable beta wave data, it is probable that she efficiently performed imagery training.

For Archer F, although the timing of shots was irregular pre-measurement, it was regular post-measurement, with the moment of a shot being at the 15th-16th second. Additionally, beta waves greatly oscillated and were irregular during the first shot pre-measurement, but gradually stabilized from the second shoot and for all shots post-measurement. Thus, there was likely a positive impact for this archer.

\section{Changes in anxiety and imagery ability}

Trait and state anxiety, and imagery ability were assessed to test the effects of neurofeedback-based imagery training. The results signaled that state and trait anxiety somewhat decreased in three of the six archers, and had little change in two archers. On the other hand, in one archer, state anxiety level was higher post-measurement compared to pre-measurement. 
Archers whose anxiety level was high pre-measurement had a lower anxiety level in post-measurement, while those in whom anxiety was low to begin with did not show a change before and after. Regarding the archer in whom the state anxiety level had risen, it is speculated based on counseling that the increase was due to stress about an upcoming competition.

Regarding changes in imagery ability between the pre- and post-measurements, in general, the imagery ability domains improved in all archers; in particular, kinesthetic imagery improved the most. The archers not only performed imagery training in the lab, but were also encouraged to train on their own by giving them imagery training cards. In archers who did imagery training on their own, anxiety reduced and imagery ability was markedly enhanced. However, among the archers who managed to train on their own approximately four times, either the anxiety level did not change or imagery ability only increased slightly. Based on the findings, real-time neurofeedback is likely to enhance self-regulation, and athletes can use it to reduce anxiety through self-regulation.

\section{Conclusion and suggestions}

\section{Conclusion}

This study was conducted with the aim of modifying a neurofeedback system developed in 2014 to fit specifically to archers, providing imagery training using the neurofeedback system, and testing the effects to enhance pre-competition imagery ability and self-regulation during competition in archers representing South Korea. The conclusions are as follows:

First, the neurofeedback system, which was modified and improved in this study, provided the archers with vibration feedback in real time if the EEG waveforms were above the threshold. The system was modified such that through real-time feedback, the archers would focus better on the imagery and the waveform would become stabilized.

Second, the integrative sports psychology approach combining imagery and neurofeedback is an effective training technique that can objectively measure athletes' psychological state and provide them with accurate feedback based on imagery questionnaires and counselling data.

Third, real-time neurofeedback training enhanced the archers' self-regulation and increased their efficiency in terms of sensations and neural activity.

Fourth, the imagery ability was boosted post-measurement when compared to pre-measurement. Of the domains of imagery, visual and kinesthetic imagery especially improved in all archers, showing that the training helped them create clearer imagery of their own performance. They were encouraged to do imagery training not only in the lab but also at home by giving them imagery training cards.

Finally, trait and state anxiety, and imagery ability were assessed to test the effects of neurofeedback-based imagery training. The levels of state and trait anxiety were somewhat reduced in three archers, but did not change in two archers. On the other hand, one archer exhibited a higher level of state anxiety post-measurement compared to pre-measurement. Regarding changes in imagery ability between the preand post-measurements, the imagery ability domains generally improved in all archers. Kinesthetic imagery improved the most.

\section{Suggestions}

Based on the findings, the following suggestions are made regarding tasks to be considered or resolved in future research:

First, an identical baseline range was used for both the pre- and post-tests. However, if baseline difficulty is varied in future studies to enhance archers' self-regulation ability through training, it will have positive impact in a competition situation.

Second, $\mathrm{C} 3, \mathrm{Cz}$, and $\mathrm{C} 4$ correspond to motor areas 
in the brain. Before a movement occurs, the premotor area activates first; at the moment when the movement is executed, the motor area activates. In the future, understanding the mechanism of brain activity along different points in time would be advanced if the changes in the relationship between the premotor and motor areas during imagery training were investigated.

Third, in this study, archers representing South Korea served as participants performing neurofeedback-based imagery training. Imagery is an important psychological factor in both open and closed sports. Accordingly, imagery training grounded in the system used in this study would help to improve the performance of athletes in diverse kinds of sports.

\section{References}

Alegre, M., Gurtubay, I, G., Labarga, A., Iriarte, J., Valencia, M., Artieda, J. (2004). Frontal and central oscillatory changes related to different aspects of the motor process: a study in go/no-go paradigms. Exp. Brain Research. 159. 14-22.

Bar-Eli, M., Dreshman, R., Blumenstein, B., \& Weinstein, Y. (2002). The effect of mental training with biofeedback on the performance of young swimmers. Applied Psychology, 51, 567-581.

Baker, S. M. (2007). Oscillatory interactions between sensorimotor cortex and the periphery. Curr Opin Neurobiol, 17, 649-655.

Barlow, D. H., Lehrer, P. M., Woolfolk, R. L., \& Sime, W. E. (2007). Principles and practice of stress management. Guilford Press.

Battaglia, C., D'Artibale, E., Fiorilli, G., Piazza, M., Tsopani, D., Giombini, A., Calcagno, G., \& di Cagno, A. (2014). Use of video observation and motor imagery on jumping performance in national rhythmic gymnastics athletes. Human Movement Science, 38, 225-234.

Becerra, J., Fernandez, T., Harmony, T. Caballero, M. I., Garcia, F., Fernandez-Bouzas, A., Santiago-Rodriguez, E., \& Prado-Alcala, R. A. (2006). Follow-up study of learning-disabled children treated with neurofeedback or placebo. Clin. EEG Neurosci. 37, 198-203.

Blumenstein, B., Bar-Eli, M., \& Tenenbaum, G. (1995). The augmenting role of biofeedback: Effects of autogenic, imagery, and music training on physiological indices and athletic performance. Journal of Sports Sciences, 13, 343-354.

Brown, P. (2007). Abnormal oscillatory synchronization in the motor system leads to impaired movement. Curr Opin Neurobiol, 17, 656-664.

Buschman, T, J., Miller, E, K. (2007). Top-down versus bottom-up control of attention in the prefrontal and posterior parietal cortices. Science 315, 1860-1862.

Callow, N., Hardy, L., \& Hall, C. (2001). The effects of a motivational general-mastery imagery intervention on the sport confidence of high-level badminton players. Research Quarterly for Exercise and Sport, 72, 389-400.

Choi, S, W. (2010). Past current and future of neurofeedback. Journal of Brain Education, 9(6), 55-73.

Collins, D. (1995). Psychophysiology and sport performance. In S. J. H. Biddle(Ed.), European Perspectives on Exercise and Sport Psychology (pp. 154-178). Leeds, UK: Human Kinetics.

Crews, D. J. (1993). Self-regulation strategies in sport and exercise. In R. N. Singer, M., Murphy, \& L. K. Tennant (Eds.), Handbook of Research on Sport Psychology (pp. 557-568). New York: Macmillan.

Crews, D. J., Lochbaum, M. R., \& Karoly, P. (2001). Self-regulation: Concepts, methods, and strategies in sport and exercise. In R. N. Singer, H. A. Hausenblas, \& C. M. Janelle(Eds.), Handbook of sport psychology(2nd ed., pp. 566-581). New York: Wiley.

deBettencourt, M, T., Cohen, J, D., Lee, R, F., Norman, K, A, \& Turk-Browne, N, B. Closed-loop training of attention with real-time brain imaging. Nature Neuroscience 18, 470-475.

Engel, A. K., Fries, P. (2010). Beta-band 
vibrations-signalling the status quo?. Curr Opin Neurobiol, 20, 156-165.

Erbil, N., Ungan, P. (2007). Changes in the alpha and beta amplitudes of the central EEG during the onset, continuation, and offset of long-duration repetitive hand movement. Brain research. 1169, 44-56.

Gatchel, R. J., \& Price, K. P. (1979). Biofeedback: an introduction and historical overview. In Gatchel and Price (Eds.), Clinical Applications of Biofeedback: Appraisal \& Status (Chapter 1), New York: Pergamon Press.

Gould, D., Tammen, V., Murphy, S. M., \& May, J. (1989). An examination of U.S. Olympic sport psychology consultants and the services they provide. The Sport Psychologist, 3, 300-312.

Gruzelier, J. H., Egner, T. (2004). Physiological self-regulation: Biofeedback and neurofeedback. Musical Excellence, 197-219.

Hall, C. R., \& Rogers, W. M. (1989). Enhancing coaching effectiveness in figure skating through a mental skills training program. The Sport Psychologist, 2, 142-154.

Hatfield, B. D., \& Hillan, C. H. (2001). The psychophysiology of sport: A mechanistic understanding of the psychology of superior performance. In R. N. Singer, H. A. Hausenblas, \& C. M. Janelle (Eds.), Handbook of Sport Psychology (2nd ed., pp. 362-386). New York: Wiley.

Hatfield, B. D., \& Landers, D. M. (1983). Psychophysiology: A new direction of sports psychology. Journal of Sport Psychology, 5, 243-259.

Hatfield, B. D., Landers, D. M., \& Ray, W. J. (1987). Cardiovascular-CNS Interactions During a self-paced, intentional attentive state: Elite marksmanship performance. Psychophysiology, 24, 542-549.

Hong, G, D., Lee, H, S., \& Jung, C, H. (2007). The Effect of Relaxation Training Program with EEG feedback on Arc Performance and Competitive State
Anxiety. Korea Sport Research, 18(5), 231-244.

Hong, S, H., Woo, M, J. (2013). Correlational Analysis of Competitive Anxiety and Frontal EEG Asymmetry Score. Korean Journal of Sport Psychology, 24(2), 1-13.

Kim, H, T., Lee, J, H. (2007). Application of biofeedback in psychological settings. The Korean Psychological Association, 6, 94-95.

Kim, Y. S., Lee, S, C., Cho, Y. I., \& Chang, T. S. (2016). Development and application of real-time neurofeedback system for shooting athletes. Korean Journal of Sport Science, 27(2), 436-446.

Kirschenbaum, D. S. (1984). Self-regulation and sport psychology: Nurturing an emerging symbiosis. Journal of Sport Psychology, 6, 159-183.

Koehn, S., Morris, T., \& Watt, A. P. (2014). Imagery intervention to increase flow state and performance in competition. The Sport Psychologist, 28, 48-59.

Kosslym, S. M., Thompson, W. L., Sukel, K. E., \& Alpert, N. M. (2005). Two types of image generation: Evidence from PET. Cognitive, Affective, and Behavioral Neuroscience, 5, 41-53.

Kwon, M, H., Kim, S, W., Jeon, H, J., Lee, G, Y., Kim, J, G., \& Woo, M, J. (2009). The influence of visual imagery on cerebral cortical activity and rifle shooting performance. Korean Journal of Sport Psychology, 20(3), 187-200.

Landers, D. (1985). Psychophysiological assessment and biofeedback. In J. Sandweiss \& S. Wolf (Eds.), Biofeedback and sport science (pp. 63-105).

Lander, D. M., Petruzzello, S. J., Salazar, W., Crews, D. J., Kubitz, K. A., Gannon, T. L \& Han, M. (1991). The influence of electrocortical biofeedback on performance in pre-elite archers. Med. Sci. Sports Exerc, 23, 123-129.

Lee, K, W., Kim, D, K. (2004). The Effect of Mental Imagery Conditions on Performance of Golf Putting in Children. Journal of Korean Physical Education Association for Girls and Women, 18(2), 107-114.

Lee, K, Y., Youn, J, C. (2001). The Effects of 
Psychological Training on Competition state Anxiety, Visual Attention, and Performance in Archery. Korean Journal of Sport Psychology, 12(1), 195-210.

Lee, S, G., Kim, E, S., \& Kim, S, O. (2009). The Qualitative analysis on imagery trait of elite archers. Korean Journal of Sport Psychology, 20(3), 155-166.

Leocani, L., Toro, C., Zhuang, P., Gerloff, C., Hallett, M. (2001). Event-related desynchronization in reaction time paradigms: a comparison with event-related potentials and corticospinal excitability. Clin. Neurophysiology. 112, 923-930.

Leung, M, C, M., Spittle, M, \& kidgell, D, J. (2013). Corticospinal excitability following short-term motor imagery training of strength task. Journal of Imagery Research in Sport and Physical Activity, 8 , 35-44.

Martin, K. A., Moritz, S. E., \& Hall, C. R. (1999). Imagery use in sport: A literature review and applied model. The Sport Psychologist, 13, 245-268.

Martens, R., Vealey, R \& Burton, D. (1990). Competition anxiety in sport. Chanpaign, IL: Human Kinetics.

Milton, J., Solodkin, A., Hlustik, P., \& Small, S. L. (2007). The mind of expert motor performance is cool and focused. Neuroimage, 35, 804-813.

Mishara, J., Gazzaley, A. (2015). Closed-loop cognition: the next frontier arrives. Trends in Cognitive Science, 19(5), 242-243.

Murphy, S. M., Jowdy, L. P., \& Durtschi, S. K. (1989). Report on the United States Olympic Committee survey on imagery use in sport: 1988. Unpublished manuscript. United States Olympic Committee Training Center, Colorado Springs, Co.

Ninaus, M., Kober, S., Witte, M., Koschutnig, K., Neuper, C., \& Wood, G. (2015). Brain volumetry and self-regulation of brain activity relevant for neurofeedback. Biol. Psychol, 110, 126-133.

Orlick, T., \& Patrington, J. (1988). Mental links to excellence. The Sport Psychologist, 2, 105-130.
Paul, M., Ganesan, S., Sandhu, J. S., \& Simon, J. V. (2012). Effect of sensory rhythm neurofeedback on psycho-physiological, electroencephalographic measures and performance of archery players. Ibnosina Journal of Medicine and Biomedical Sciences, 4(2), 32-39.

Petruzello, S. J., Landers, D. M., \& Salazar, W. (1991). Biofeedback and sport/exercise performance: Applications and limitations. Behavior Therapy, 22, 379-392.

Schwartz, G. E. (1979). Disregulation and systems theory: A biobehavioral framework for biofeedback and behavioral medicine. In N. Birbaumer \& H. E. Kimmel (Eds.), Biofeedback and self-regulation (pp. 19-48). NY: Erlbaum.

Sim, J, Y. (2004). Competitive state anxiety and competition performance and EEG changes of Frontal in shooting players according to EEG Bio-Feedback training. Korean Journal of Sport Psychology, 15(2), 75-92.

Smith, D. (1987). Conditions that facilitate the development of sport imagery training. The Sport Psychologist, 1, 237-247.

Stancak, A., Pfurtscheller, G. (1996). Event-related desynchronisation of central beta-rhythms during brisk and slow self-paced finger movements of dominant and nondominant hand. Cognitive Brain research. 4, 171-183.

Ste-Marie, D, M., Law, B., Rymala, A, M., Craig Halld, J, O, \& McCullagh, P. (2012). Observation interventions for motor skill learning and performance: An applied model for the use of observation. International Review of Sport and Exercise Psychology, 1, 1-32.

Vealey, R. S., \& Greenleaf, C. A. (2001). Seeing is believing: Understanding and using imagery in sport. In J. M. Williams (4th ed.). Applied Sport Psychology: Personal growth to peak performance (pp. 247-283). Mountain View, CA: Mayfield.

Wheaton, L., Fridman, E., Bohlhalter, S., Vorbach, S., Hallett, M. (2009). Left parietal activation related to 
planning, executing and suppressing praxis hand movement. Clin. Neurophysiology. 120, 980-986.

Yun, Y, K., Kim, W, B., \& Lim, T, H. (2006). Analytic hierarchy process to examine factors influencing sports performance. Korean Journal of Sport Psychology, 17(1), 1-11.

Zaichknowsky, L. D. (1983). The use of biofeedback for self-regulation of performance states. In L. E. Unestahl (Ed.). The mental aspects of gymnastics (pp. 95-105). Orebro, Seden: Veje.

Zaichknowsky, L. D., \& Fuchs, C. Z. (1988). Biofeedback applications in exercise and athletic performance. Exercise and Sport Sciences Reviews, 16, 381-421.

Zhang, Y., Chen, Y., Bressler, S, L., Ding, M. (2008). Response preparation and inhibition: the role of the cortical sensorimotor beta rhythm. Neuroscience, 156, 238-246. 